\title{
Review of Timber connections: Connector Plate, Cleats, Studies and Dovetail Connections
}

Kristopher Orlowski*

Department of Infrastructure Engineering, The University of Melbourne, Australia

\section{Timber Connections}

The strength of a building relies heavily upon the transfer of load from one connection

ISSN: 2639-0574

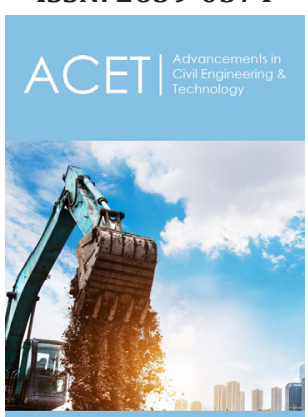

${ }^{* 1}$ Corresponding author: Kristopher Orlowski, Department of Infrastructure Engineering, The University of Melbourne ,Australia

Submission: 㯺 August 08, 2019

Published: 㳑August 21, 2019

Volume 3 - Issue 4

How to cite this article: Kristopher Orlowski. Review of Timber connections: Connector Plate, Cleats, Studies and Dovetail Connections. Adv Civil Eng Tech. 3(4). ACET.000568.2019.

DOI: 10.31031/ACET.2019.03.000568

Copyright@ Kristopher Orlowski, This article is distributed under the terms of the Creative Commons Attribution 4.0 International License, which permits unrestricted use and redistribution provided that the original author and source are credited. to another [1,2]. A solid and reliable connection method must be utilized to increase the strength of timber panel and enable the structure to withhold an excessive amount of stress [3-5]. In wood buildings, an effective connection will provide the building with strength and ductility [6]. However, there are many connections needed in a wooden structure therefore an economical and durable connection is required to assemble a prefabricated panel quickly and inexpensively in mass production [6].

\section{Connector Plate}

A simple and affordable connector typically used in walls for joining the horizontal plates is the nail plate. This type of connection is more commonly used as a horizontal connection however can be utilized in a vertical direction if the load is not exceeding the safety limits. Pryda provides a wide variety of nail plates suitable for different structures and loads [7]. The connector plate and knuckle nail plate are galvanized steel connectors with in-built, bent up knuckle nails. They are applied by firmly hammering or pressing the in-built nails into each side of the timber to be connected the latter of which can be automated with a press or roller. Typically, there are 4 columns by 8 rows of in-built nails with an approximate capacity per nail of $280 \mathrm{~N}$ in the parallel direction and $95 \mathrm{~N}$ perpendicular. To increase the load capacity of the connection, holes are present within the nail plate to apply external nails through the nail plate and into the wood (Table 1).

Table 1: Connector plate bearing capacity.

\begin{tabular}{|c|c|}
\hline Connector & Loading Capacity Per Nail (N) \\
\hline Parallel & 280 \\
\hline Perpendicular & 95 \\
\hline
\end{tabular}

Heavy Duty Pre-Punched Plate

Where a heavier load is required to be supported, a heavy duty pre-punched plate can be utilized. These similar to normal nail plates are made from galvanized stainless-steel plates with multiple holes pre-punched through the plate for nails to be driven into. Nails must be driven into every hole in order to maximize the strength provided by this nail plate. There are a variety of sizes and load capacities provided making these plates ideally suited for onsite and offsite construction (Table 2). These typically range from $75 \mathrm{~mm}$ to $150 \mathrm{~mm}$ wide with maximum tensions and shear from $35 \mathrm{kN}$ and $21 \mathrm{kN}$ up to $70 \mathrm{kN}$ and $42 \mathrm{kN}$ [7].

Table 2: Heavy Duty pre punched plate.

\begin{tabular}{|c|c|c|}
\hline Plate Width & Max Tension $(\mathbf{k N})$ & Max Shear $(\mathbf{k N})$ \\
\hline $75 \times 1.0$ & 35.2 & 21.2 \\
\hline $100 \times 1.0$ & 46 & 27.6 \\
\hline $150 \times 1.0$ & 70.2 & 42.5 \\
\hline
\end{tabular}

Purlin Cleat

For wall framing connections this consist of a vertical to horizontal connection that can support the load of structures above. The Purlin Cleat is a strong and versatile framing 
connection as it provides a rigid connection for trusses, rafters and beams to wall plates. This connection is especially suited for concealed applications where the steel material and nails are hidden from view [8]. The connection consists of a 90-degree angle nail plate with pre-punched holes on the top and bottom of each side. Nails are then driven through the holes in the steel plate and into the timber. The purlin cleat should be applied to both sides of the stud, as it will increase the bearing capacity significantly however this makes the process difficult to automate. In structures with high loads, a purlin cleat is mostly used however the installation of this connection is not the most durable, as external nails must be used.

\section{Stud Ties}

A simple and durable but low strength connection for framing applications is the tie down connection however the installation of which is generally conducted manually. This type of connection would be useful when building low-rise structures and are easily installed. Specifically, stud ties are a type of tie down connection that consists of a U-shaped nail plate with in-built nails on the top and bottom sections of the steel [7]. These plates are then placed on the top of the frame with the bottom half of the plate into the studs. The inbuilt nails are then nailed into position providing strength and stability to the structure. There are 2 types of stud ties; double sided and single sided, which are typically manufactured. The double-sided stud tie is applied onto both sides of the wooden stud whereas the single sided stud tie is only applied to one side (Table 3). Because of this the bearing capacity of the double-sided tie is comparatively higher however more cumbersome to achieve in assembly line with flat tables.

Table 3: Purlin cleat and stud ties capacity.

\begin{tabular}{|c|c|}
\hline Joint & Bearing Capacity Per Connection (kN) \\
\hline Purlin Cleat & 11 \\
\hline Double Sided Stud Tie & 7 \\
\hline Single Sided Stud Tie & 5.7 \\
\hline
\end{tabular}

\section{Sherpa Dovetail Connection}

For a balance of durability and strength, a dovetail connection may be preinstalled into both faces of wood. Sherpa connectors provide a wide range of pre-engineered connections, which are quick to install, safe and efficient in construction [9]. This type of connection is prefabricated into the wooden structure where they interlock into place and form a tight fit. The forces are transferred perpendicular to the connection direction and can withstand a large tension force (Figure 1). Two plates, one indented and one protruding outwards, are installed onto the wooden faces of the connection. From there nails are drilled into the sides of the plate at different angles to increase the strength of the connection. During assembly onsite, each wooden panel can then be slotted next to each other through the dovetail quick and efficiently. The dovetail connection is a concealed type of connection where in the case of a fire; it will be protected by layers of wood around the connection (Figure 2). The different types of dovetail connectors are specified in Table 4 with their bearing capacities.
Table 4: Sherpa dovetail connection bearing capacity [9].

\begin{tabular}{|c|c|c|}
\hline Connector & Screws Required & $\begin{array}{c}\text { Bearing Capacity Per Connection } \\
\text { (kN) }\end{array}$ \\
\hline XS 20 & 25 & 20 \\
\hline S 20 & 25 & 20 \\
\hline M 40 & 30 & 40 \\
\hline L 80 & 29 & 80 \\
\hline XL 250 & 48 & 250 \\
\hline XXL 300 & 59 & 300 \\
\hline
\end{tabular}

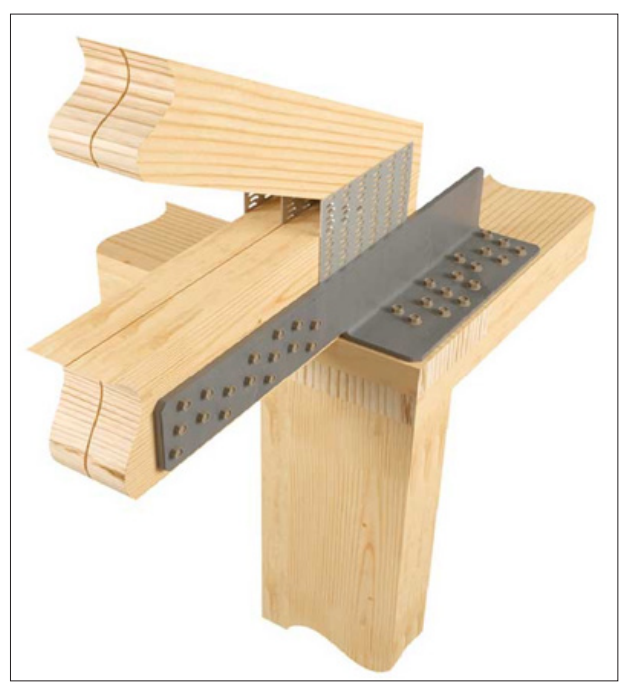

Figure 1: Drag-strut connector [10].

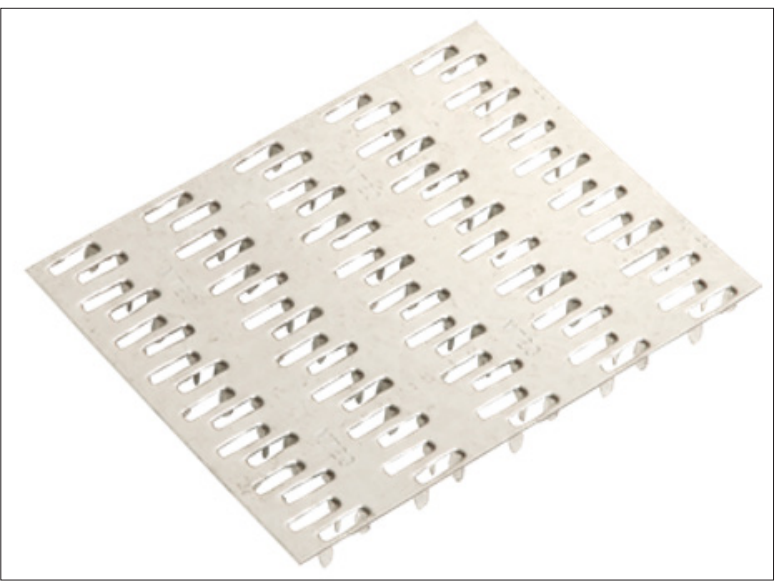

Figure 2: Timber connector plate [11].

\section{Drag-strut Connector}

Drag-strut connector transfers the diaphragm shear forces from the girder truss or beam to the shear-walls. The main purpose of a drag strut connector is to connect a beam or truss to the top plate of a colinear bearing wall, thereby completing the load path and allowing loads to be transferred out of the roof or floor sheathing into the wall system where the shear-walls are. Such a beam or truss is referred to as a load "collector" or "drag strut" (Figure 3). The key to this connection is that it uses self-drilling screws to create a 
superior connection to that achieved with a similar connector and bolts [12].

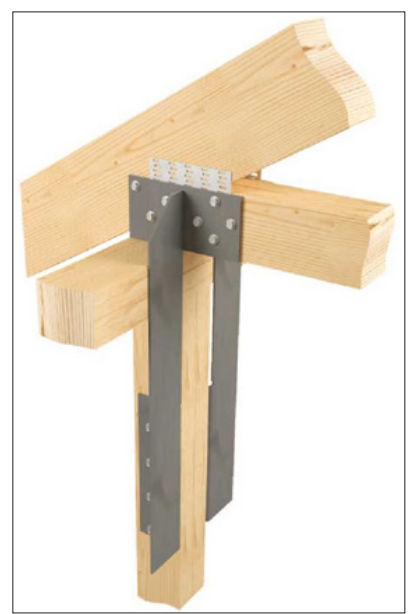

Figure 3: Uplift resistant stud tie connector [8].

\section{References}

1. Orlowski K (2015) Synchronization of sustainable development with land development. Sustainable Development Research in the AsiaPacific Region, pp. 449-463.

2. Orlowski K (2019) Assessment of manufacturing processes for automated timber-based panelized prefabrication. Buildings 9(5): 125.
3. Orlowski K, Shanaka K, Mendis P (2018) Design and development of weatherproof seals for prefabricated construction: A methodological approach. Buildings 8(9): 117.

4. Orlowski K, Shanaka K, Mendis P (2018) Manufacturing, modeling, implementation and evaluation of a weatherproof seal for prefabricated construction. Buildings 8(9): 120

5. Orlowski KA (2018) Synchronization of sustainable development with land development, in sustainable development research in the Asia-pacific region: education, cities, infrastructure and buildings. In: Leal Filho W, Rogers J, Iyer-Raniga U (Eds.), Springer International Publishing: Cham, Switzerland, pp. 449-463.

6. https://www.woodworks.org/wp-content/uploads/ConnectionOptions-For-Wood-Frame-Buildings-CEU-Dec-2015.pdf

7. https://www.pryda.com.au/

8. https://www.mitek-us.com/products/truss-rafter-tiedowns/girdertiedowns/RUSC/

9. Innovating with Wood (2012) A case study showcasing four dimenstration projects $1(1): 32$.

10. https://www.mitek-us.com/products/plated-truss/drag-strutconnectors/LDSC\%20/\%20DSC/

11. https://www.mitek-us.com/products/steel-plates/MT-Plates/

12. Pryor SE (2003) Inventor; Simpson Strong-Tie Co Inc, assignee. Drag strut connector. United States patent US 6,655,096.

For possible submissions Click below: 